\title{
CRIANÇAS DE ETNIAS CIGANAS NO BRASIL: PROCESSOS DE ESCOLARIZAÇÃO NA EDUCAÇÃO BÁSICA
}

\author{
CHILDREN OF GYPSY ETHNAS IN BRAZIL: SCHOOLING \\ PROCESSES IN BASIC EDUCATION
}

\section{HIJOS DE ÉTNAS GITANAS EN BRASIL: PROCESOS DE ESCUELA EN EDUCACIÓN BÁSICA}

\author{
Monique de Oliveira da Silva Rodrigues \\ https://orcid.org/0000-0001-8796-466X \\ Ercília Maria Angeli Teixeira de Paula \\ https://orcid.org/0000-0002-8619-7558
}

\begin{abstract}
Resumo: Ao longo da história pode-se observar que as etnias ciganas foram tratadas com desapreço em diferentes sociedades. Esse é um dos fatores de as populações de etnias ciganas viverem à margem da sociedade, sem acesso aos direitos básicos como a educação. O objetivo geral desse artigo foi identificar como são realizados os encaminhamentos dos processos escolares para as crianças de etnias ciganas na Educação Básica brasileira. Os objetivos específicos foram: descrever historicamente a cultura das etnias ciganas que residem no Brasil; identificar as políticas públicas de educação no Brasil para as crianças de etnias ciganas; constatar por meio de revisão de literatura se o currículo da Educação Básica do Brasil visibiliza as etnias ciganas. O referencial teórico foi fundamentado nos autores que discutem as Etnias Ciganas: Pinto (2010), Moonen (2011), Durante (2014); e nos autores que fazem a discussão dos Estudos Culturais: Silva (1999) e Hall (2006). A metodologia utilizada foi a revisão de literatura (BIANCHETTI e MACHADO, 2006) através da análise da produção acadêmica do Brasil, que trata dos estudos das crianças de etnias ciganas. Os resultados revelaram que apesar de existirem documentos oficiais brasileiros que garantem o direito a educação para essas crianças, esses não são garantidos. A história mostra que desde o período da colonização no Brasil os ciganos sofrem com a discriminação e o preconceito da sociedade. Quanto aos currículos na educação básica, as crianças de etnias ciganas ainda são invisibilizadas no Brasil.
\end{abstract}

Palavras-chave: Crianças Ciganas. Educação Básica. Estudos Culturais.

\begin{abstract}
Throughout history it can be seen that Roma people have been treated with contempt in different societies. This is one of the reasons why Roma people live on the fringes of society without access to basic rights such as education. The general objective of this paper was to identify how school process referrals are carried out for Roma children in Brazilian Basic Education. The specific objectives were: to describe historically the culture of the gypsy ethnic groups residing in Brazil; identify public education policies in Brazil for Roma children; To verify through literature review whether the curriculum of Basic Education in Brazil makes Roma
\end{abstract}


gypsies visible. The theoretical framework was based on the authors who discuss the Roma: Pinto (2010), Moonen (2011), Durante (2014); and in the authors who discuss Cultural Studies: Silva (1999) and Hall (2006). The methodology used was the literature review (BIANCHETTI and MACHADO, 2006) through the analysis of the academic production in Brazil, which deals with the studies of Roma children. The results revealed that although there are official Brazilian documents that guarantee the right to education for these children, they are not guaranteed. History shows that since the colonization period in Brazil Gypsies have suffered from discrimination and prejudice from society. As for curricula in basic education, Roma children are still invisible in Brazil.

Keywords: Gypsy Children. Basic Education. Cultural Studies.

Resumen: A lo largo de la historia se puede ver que los romaníes han sido tratados con desprecio en diferentes sociedades. Esta es una de las razones por las cuales los romaníes viven al margen de la sociedad sin acceso a derechos básicos como la educación. El objetivo general de este documento fue identificar cómo se llevan a cabo las referencias del proceso escolar para los niños romaníes en la educación básica brasileña. Los objetivos específicos fueron: describir históricamente la cultura de los grupos étnicos gitanos que residen en Brasil; identificar políticas públicas de educación en Brasil para niños romaníes; Para verificar a través de la revisión bibliográfica si el plan de estudios de Educación Básica en Brasil hace visibles a los gitanos romaníes. El marco teórico se basó en los autores que discuten sobre los romaníes: Pinto (2010), Moonen (2011), Durante (2014); y en los autores que discuten Estudios Culturales: Silva (1999) y Hall (2006). La metodología utilizada fue la revisión de la literatura (BIANCHETTI y MACHADO, 2006) a través del análisis de la producción académica en Brasil, que se ocupa de los estudios de niños romaníes. Los resultados revelaron que, aunque existen documentos oficiales brasileños que garantizan el derecho a la educación de estos niños, no están garantizados. La historia muestra que desde el período de colonización en Brasil, los gitanos han sufrido discriminación y prejuicios de la sociedad. En cuanto a los planes de estudio en educación básica, los niños romaníes siguen siendo invisibles en Brasil.

Palabras clave: Niños Gitanos. Educación Básica. Estudios Culturales.

\section{INTRODUÇÃO}

A escolarização das crianças de etnias ciganas ainda é pouco discutida nas produções acadêmicas e nas práticas educacionais das escolas de educação básica do Brasil. Faz-se necessário, em qualquer ambiente educacional, não apenas o cumprimento dos currículos, mas humanizar, formar para a cidadania e para a emancipação. Nos currículos é preciso respeitar as diferenças culturais dos alunos, as particularidades e as características de cada região em que residem.

Libâneo (2005) afirma que a educação é um processo social que ocorre em todos os espaços sociais e quando esse processo ocorre de forma plena contribui com o exercício da cidadania. Por isso a necessidade de políticas públicas atuais e efetivas que garantam a educação para todos os indivíduos e com igualdade de direitos.

De acordo com Moonen (2011, p.13) povos de etnias ciganas e diversos pesquisadores afirmam que há pelo menos três grandes grupos ciganos, são eles:

1. Os Rom, ou Roma, que falam a língua romani; são divididos em vários subgrupos, com denominações próprias, como os Kalderash, Matchuaia, Lovara, Curara 
e outros. São predominantes nos países balcânicos, mas a partir do Século 19 migraram também para outros países europeus e para as Américas. 2. Os Sinti, que falam a língua sintó, são mais encontrados na Alemanha, Itália e França, onde também são chamados Manouch. 3. Os Calon ou Kalé, que falam a língua caló, os 'ciganos ibéricos', que vivem principalmente em Portugal e na Espanha, onde são mais conhecidos como Gitanos, mas que no decorrer dos tempos se espalharam também por outros países da Europa e foram deportados ou migraram inclusive para a América do Sul. (MOONEN, 2011, p.13).

Os indivíduos de etnias ciganas são marcados historicamente por seus valores culturais e sociais específicos de seus povos, como os diferentes espaços de moradias, em sua maioria nômades, as roupas coloridas, o uso de dialetos para a comunicação no seio da comunidade, vendas ambulantes, misticismo e mendigações como fonte de renda, entre outros. As características ao mesmo tempo que os identificam, os diferenciam, segregando as populações de etnias ciganas ao longo da história.

Borges (2007) afirma que o desconhecimento da trajetória dos povos de etnias ciganas e as contradições aos valores ocidentais, são explicações para os medos, desconfianças e estereótipos que as sociedades não-ciganas alimentam em relação a esses povos. $O$ desconhecimento com relação aos valores ciganos tem gerado a intolerância, o preconceito e o desrespeito para com essas etnias por diferentes gerações.

Rodrigues (2019) declara que as sociedades sempre tiveram mais facilidade em julgar as diferentes etnias ciganas por desconhecimento de sua natureza e a maioria não busca inteirar-se. O medo, a ignorância e o desconhecer o diferente projetam a construção de pré-conceitos e potencializa a marginalização das minorias.

As etnias ciganas sofrem com os processos de exclusão e de discriminação social por parte das políticas governamentais e das sociedades não-ciganas, que os desprezam nos diferentes espaços de convivência social, dentre eles o espaço escolar. Ventura (2004) assevera a necessidade de se desenvolver pesquisas despojadas de preconceito, que mostrem as diferentes culturas das etnias ciganas, apresentando suas particularidades na interação social.

O objetivo geral deste artigo foi identificar como são realizados os encaminhamentos dos processos escolares para as crianças de etnias ciganas na Educação Básica do Brasil. Quantos aos objetivos específicos foram: descrever historicamente a cultura das etnias ciganas que residem no Brasil; identificar as políticas públicas de educação no Brasil para as crianças de etnias ciganas; constatar por meio de revisão de literatura se o currículo da Educação Básica do Brasil visibiliza as etnias ciganas.

Como referencial teórico usamos as obras de autores que discutem as Etnias Ciganas como: Pinto (2010), Moonen (2011), Durante (2014); e autores que discutem sobre os Estudos Culturais: Silva (1999) e Hall (2006).

A metodologia utilizada na construção desse artigo foi a revisão de literatura (BIANCHETTI E MACHADO, 2006). Este artigo foi realizado a partir da análise da produção aca- 
dêmica brasileira, que tem como temática os estudos das crianças de etnias ciganas para a realização de uma dissertação de mestrado.

Na sessão a seguir trataremos sobre a itinerância e a cultura dos povos de etnias ciganas no Brasil.

\section{A ITINERÂNCIA DOS POVOS CIGANOS}

A história das etnias ciganas foi escrita por não-ciganos e de acordo com Guimarais (2012), por esse motivo, a origem dos povos ciganos é pouco conhecida. Para Fraser (1997, p. 68) "a história dos povos ciganos não foi abordada em livros ou escolas por falta de registros escritos, assim a sociedade não tem nenhuma referência desse determinado grupo de pessoas". A teoria com maior aceitação por eles os identifica como um povo originário da Índia, formada por membros de uma casta de militares, que aproximadamente nos anos 1000, teria iniciado dispersão pelo mundo em razão de uma série de invasões islâmicas na região.

Bareicha (2013, p. 14) afirma que "os antepassados dos ciganos eram nômades estrangeiros de pele escura, de acordo com registros de outros povos europeus, que indicam a ligação com os ciganos". Ainda de acordo com a autora, conforme a região europeia em que chegavam eram considerados feiticeiros, domadores e pessoas que previam o futuro.

Para Moonen (2011), o termo cigano tem origem na construção teórica sobre as percepções da população europeia do século XV e esse conceito vem da generalização quanto a diversidade étnica, seja ela a cultura, os dialetos e até mesmo a origem territorial.

De acordo com Bareicha (2013) os ciganos portugueses foram deportados para o Brasil a partir do ano de 1686, segundo os documentos de Portugueses que afirmam que os indivíduos de etnias ciganas deveriam ser deportados para as colônias africanas e para o Brasil, especificamente para o Estado do Maranhão, da Bahia e de Pernambuco. Ao longo dos anos os povos de etnias ciganas iniciaram sua itinerância por todo o país.

\footnotetext{
[...] ao mesmo tempo em que ser nômade é percebido como uma necessidade do grupo cigano, e que isso faz parte de sua sobrevivência, apesar das mudanças sociais criadas a partir da Revolução Industrial nas grandes cidades, pois essa é uma característica cigana, de suas raízes, sentida como parte de sua gente, a forma de ser andante. E como eles mesmos dizem, "a gente anda", é prazeroso, mesmo havendo momentos de dificuldades, configurando-se essa ação como parte do ser cigano, do sentir-se cigano. (BAREICHA, 2013, p. 21)
}

Atualmente, no Brasil, os três grupos de etnias ciganas estão presentes e eles estão distribuídos em todos os Estados do país e no Distrito Federal. Os indivíduos dessas etnias residem desde endereços sofisticados até as periferias das grandes e pequenas cidades. No decorrer da história indivíduos ciganos foram se sedentarizando e atualmente deles têm 
residência fixa, por motivos diversos, como o casamento com pessoas de cultura diferente, para ter o direito a programas do governo de distribuição de renda, entre outros.

Para os autores, Pinto (2010), Martins (2011), Bareicha (2013) e Durante (2014) as crianças de etnias ciganas na faixa etária de quatro anos de idade estão sendo matriculadas nas escolas de ensino regular, mudando aos poucos a cultura dessas comunidades, tornando o ingresso na Educação Infantil como algo natural.

Um dos motivos para as crianças serem matriculadas na Educação Infantil, é porque há alguns anos atrás no país, os programas de transferência direta de renda, como o Bolsa Família, passaram a exigir frequência escolar acima de $85 \%$ mensalmente do aluno em que a família é beneficiária.

Os indivíduos de etnias ciganas realizam atividades itinerantes tradicionais de sua cultura como o comércio, vendas ambulantes, leitura de cartas e mãos ("draba”), e criação de animais (gados, cavalos, porcos e galinhas).

Conforme o documento "Ciganos - Documento orientador para os sistemas de ensino" do Ministério da Educação (BRASIL, 2014), no Brasil observa-se um número crescente, embora ainda pequeno, de profissionais de etnias ciganas atuantes em áreas como a saúde, a educação e as artes em geral.

A Embaixada Cigana (2017) em seu site trata sobre a etnia Calon e afirmam que etnia é um conjunto de características que um povo possui, como o dialeto, a moradia, as vestimentas, as artes e outros.

Os Calon, de acordo com o site da Embaixada Cigana (2017), vivem em terrenos públicos ou privados, ocupados, arrendados ou cedidos, que possibilitam a instalação tendas para formar acampamentos. Os terrenos se localizam em lugares estratégicos para facilitar o comércio e o trabalho dos indivíduos que fazem parte da comunidade.

De acordo com Bareicha (2013), a chefia do acampamento é escolhida pelas qualidades que possui, os indivíduos de etnias ciganas valorizam mais a honestidade, a coragem e a moral, prezam também por quem mantenha a calma nos momentos difíceis da comunidade e solucione os problemas do grupo.

Com relação às roupas, os homens se vestem bota, chapéu de vaqueiro e cinturão, já as mulheres usam saias ou vestidos longos com cores vivas, tecidos floridos e com fitas coloridas, costumam usar os cabelos longos, trançados e enfeitados com flores. Muitos indivíduos de etnias ciganas costumam por dentes de ouro, uma característica que faz com que os indivíduos não-ciganos os identifiquem como pertencentes a essas etnias.

Bareicha (2013) explica que o casamento é parte da tradição cigana e envolve toda a comunidade cigana, outras comunidades ciganas que participam da celebração, simbolizada pelo casal de noivos. Os indivíduos ciganos têm muito respeito pela união matrimonial e não toleram o adultério.

Ainda de acordo com o referido autor, os indivíduos ciganos prezam a educação informal da linguagem e as atribuições de diferentes papeis, que se inicia no nascimento até o momento em que constituem uma outra família. 
As meninas aprendem desde cedo a cuidar dos afazeres domésticos e que, na adolescência, irão se casar com um rapaz da comunidade. Os meninos quando completam doze anos passam a viajar com os pais que trabalhar com vendas ou aprendem a cuidar dos animais que a família cria.

Os indivíduos de etnias ciganas apreciam as artes. Na região Sul e Sudeste do país, a maioria dos povos ciganos gostam de ouvir as músicas sertanejas, na região Norte e Nordeste do país apreciam, em sua maioria, o forró, ritmo cultural e característico dessas regiões.

$\mathrm{Na}$ comunicação eles usam a Língua Portuguesa como língua oficial, mas incluíram o romani como um paradialeto.

E, convém destacar o que Romani (2013) afirma sobre os indivíduos ciganos:

Nem todos são pobres, nem todos morenos, nem todos analfabetos. Poucos são ricos, raros dançam em volta da fogueira ou usam roupas extravagantes, do tipo que se vê nas novelas e nos bailes à fantasia. Mas uma coisa eles têm em comum: uma extraordinária capacidade de assimilar o patrimônio cultural de onde vivem, a fim de amenizar o preconceito que enfrentam. (ROMANI, 2013, p. 27)

Na construção do documento "Ciganos - Documento orientador para os sistemas de ensino" do Ministério da Educação (BRASIL, 2014), um mapeamento realizado identificou 291 (duzentos e noventa e um) acampamentos ciganos no território nacional brasileiro. A população de etnias ciganas está distribuída em vinte e um estados brasileiros, sendo os de maior concentração: Bahia, Minas Gerais e Goiás. Estima-se que atualmente existam cerca de 800.000 ciganos no Brasil, com base no Documento do Ministério da Educação (BRASIL, 2014).

Mesmo sendo invisibilizadas as etnias ciganas estão presentes em todas as regiões do Brasil, conforme segue:

No Norte do país, região formada por setes Estados, os ciganos estão presentes em apenas dois Estados, o Pará e o Tocantins, e em três cidades;

Na região Nordeste, onde nove Estados a compõem, os ciganos estão presentes em todos eles e em cento e quarenta e uma cidades;

Na região Centro-Oeste, que é composta por três Estados os ciganos estão presentes em todos eles, e foram mapeados em quarenta e três cidades;

Na região Sul também composta por três Estados, os ciganos foram mapeados em todos eles e em noventa e quatro cidades da região;

E, na região Sudeste, formada por quatro Estados, os ciganos também estão presentes em todos eles, em cento e quarenta e sete cidades.

O site Cultura Mix ${ }^{1}$ (BRASIL, 2013) informa que a maior comunidade cigana, que reside no Brasil, se localiza no Estado da Paraíba, a 420 km de João Pessoa e esta não é nômade há mais de vinte e cinco anos.

1 Endereço do site Cultura Mix: http://cultura.culturamix.com/curiosidades/ciganos-no-brasil-origem-e-caracteristicas-do-povo. 
A seguir discutiremos as Políticas Públicas da Educação junto dos Estudos Culturais, para as crianças de etnias ciganas.

\section{POLÍTICAS PÚBLICAS EDUCACIONAIS E CURRÍCULO PARA AS CRIANÇAS DE ETNIAS CIGANAS DO BRASIL}

A Constituição Federal (BRASIL, 1988) no artigo 6², afirma que a educação é um direito social, o poder público tem a responsabilidade de oferecer vagas na Educação Básica para todos. Na Lei de Diretrizes e Bases da Educação Nacional (LDB) nº 9.394/96 (BRASIL, 1996) o artigo $4^{\circ}$, inciso $X$, afirma que todos em idade escolar devem ter acesso a vaga na escola pública de Educação Infantil ou de Ensino Fundamental mais próxima de onde reside a partir do dia em que completar quatro anos de idade.

Caso a criança, o adolescente ou o jovem seja de uma família itinerante, o Código Civil (BRASIL, 2002), no parágrafo único do artigo $72^{\circ}$ e o caput do artigo $73^{\circ}$ afirmam que o domicílio da pessoa natural, que não tenha residência habitual, sedentarizada, o lugar onde ela for encontrada. Portanto, os indivíduos de etnias ciganas, que tem por característica e cultura a itinerância, encontram-se em situação domiciliar garantida por lei.

A Constituição Federal (BRASIL, 1988), o Estatuto da Criança e do Adolescente-ECA (BRASIL, 1990) e a LDB (BRASIL, 1996) não exigem para a matrícula de crianças, adolescentes e/ou jovens tempo de residência em determinada localidade. Por isso as crianças de etnias ciganas não devem encontrar obstáculos para o acesso à educação.

Em 2012, o Ministério da Educação publicou o parecer CNE/CEB No: 14/2011 no D.O.U. de 10/5/2012 (BRASIL, 2012), sobre as diretrizes para o atendimento educacional de crianças, adolescentes e jovens com famílias itinerantes. A iniciativa partiu do Conselho Municipal de Educação de Canguçu, no Estado do Rio Grande do Sul. O tema da consulta foi a situação vivenciada por estudantes de diferentes grupos sociais, que por motivos diversos como, a cultura, o trabalho dos provedores da família, a saúde, entre outros, se encontram nessa condição de itinerância.

Sobre as condições escolares destes estudantes o parecer CNE/CEB N: 14/2011 afirma que:

A itinerância tem afetado, sobremaneira, a matrícula e o percurso na Educação Básica de crianças, adolescentes e jovens (...) A consequência dessa condição tem sido a sujeição à descontinuidade na aprendizagem, levando ao insucesso e ao abandono escolares, impedindo-lhes a garantia do direito à educação. As orientações e encaminhamentos dados pelas instituições escolares à matrícula dos estudantes em situação de itinerância geralmente não são de conhecimento público, ficando, na maioria das vezes, à mercê da relação estabelecida entre a escola e a família em contextos específicos. (BRASIL, 2012, p. 24) 
Com o parecer CNE/CEB No: 14/2011 (BRASIL, 2012) é possível identificar que os encaminhamentos pedagógicos adotados pelas instituições escolares não chegam a conhecimento público. Por meio deles, seria possível identificar quais obtiveram sucesso e não prejudicaram o desenvolvimento escolar destes alunos, estes encaminhamentos poderiam ser propagados para que não só alguns alunos itinerantes tenham acesso pleno a educação, mas todos.

O Documento do Ministério da Educação "Ciganos: Documento orientador para os sistemas de ensino" (BRASIL, 2014) afirma que os sistemas de ensino, público ou privado, de Educação Básica, devem assegurar a matrícula para os estudantes em situação de itinerância. Esses estabelecimentos não podem fazer imposições por preconceito, mediante autodeclaração ou declaração do responsável de que o indivíduo vive em situação de itinerância, pois o acesso à Educação é um direito fundamental. Portanto, para jovens e adultos pode ser usada a autodeclaração.

Ainda de acordo com o Documento do Ministério da Educação "Ciganos: Documento orientador para os sistemas de ensino" (BRASIL, 2014), a instituição de educacional que receber matrícula de estudantes de etnias ciganas deverá comunicar o fato à Secretaria de Educação ou ao órgão regional imediato. Se o aluno itinerante não tiver certificado ou relatório da escola anterior, será inserido na série correspondente a sua idade, após avaliação da aprendizagem, realizada pela instituição de ensino que o receber.

O Projeto de Lei do Senado N²48 de 2015 (BRASIL, 2018) criou o Estatuto do Cigano e defende direitos para a melhoria da qualidade de vida dos indivíduos de etnias ciganas no Brasil. $\mathrm{O}$ artigo $\mathrm{n}^{\circ} 4$ afirma que os indivíduos de etnias ciganas têm direito ao acesso à educação básica, conforme a LDB, Lei n 9.394, de 20 de dezembro de 1996, e à participação nas atividades culturais e educacionais, providas pelo poder público e entidades privadas.

No capítulo II, artigo $5^{\circ}$, o Projeto de Lei do Senado №248 de 2015, discorre que:

Art. $5^{\circ} \mathrm{O}$ poder público promoverá: I - o incentivo à educação básica da população cigana, sem distinção de gênero; II - o apoio à educação da população cigana por meio de entidades públicas e privadas; III - a criação de espaços para a disseminação da cultura da população cigana. Art. $6^{\circ} \mathrm{Fica}$ assegurada à criança e ao adolescente ciganos o direito previsto no art. 29 da Lei n 6.533, de 24 de maio de 1978. Art. $7^{\circ}$ Nos estabelecimentos de ensino fundamental e de ensino médio, públicos e privados, é obrigatório o estudo da história geral da população cigana, observado o disposto na Lei $n^{\circ}$ 9.394, de 1996. (BRASIL, 2018, p. 3)

Portanto, é possível observar que existem leis garantindo o direito à educação dos povos de etnias ciganas, no entanto, o cotidiano escolar incentiva esses indivíduos a mascarar sua cultura, deixá-la de lado e se adequar aos padrões de culturas não-ciganas que estão em maior evidência nos espaços educacionais. 
A partir da criação desse Estatuto do Cigano (BRASIL, 2018) objetiva-se que os indivíduos de etnias ciganas sejam respeitados em suas culturas e particularidades nas escolas e em diferentes contextos, e um dos meios disso acontecer é pelo currículo a ser trabalhado.

O currículo, de acordo com Silva (1999), não deve ser uma seleção de saberes, mas os conteúdos selecionados e hierarquizados são aspectos a serem analisados. As instituições escolares, na maior parte do tempo, são mantenedoras do sistema vigente social. Embora, existam também instituições educacionais que são espaços de interação, criticidade, de transformação social e resistência aos padrões estabelecidos pela sociedade majoritária.

Silva (1999) afirma que o currículo é como uma narrativa étnica e defende o pensamento curricular crítico, e aponta a discussão das desigualdades sociais como uma das formas de romper com a reprodução das desigualdades sociais já existentes.

O autor afirma a necessidade de uma configuração do repertório educacional que não só observe, mas considere as questões de etnia e gênero, pois "é através do vínculo entre conhecimento, identidade e poder que os temas da raça e da etnia ganham seu lugar no território curricular" (Silva, 1999, p. 101).

Santomé (1995) discorre que uma das finalidades principais do currículo educacional é formar os alunos, solidários e democráticos para a sociedade. Porém, para alcançar esses objetivos é necessário selecionar conteúdos, selecionar também os recursos e aprendizagens, mas também rever os modelos de organização e avaliação.

O planejamento do currículo e sua posterior colocação em ação - necessária para conseguir metas similares - estão muito longe de uma visão acumulativa, bancária, de conteúdos para serem adquiridos pelos/as estudantes, como se esses/as fossem gravadores de som. Muitas propostas de escolarização mantêm ainda uma forte estrutura fordista, no sentido de que seu modo de funcionamento se assemelha ao da cadeia de montagem de uma grande fábrica. Assim, os alunos/as se posicionam de forma fixa em sua carteira e diante deles/as vão passando diferentes matérias e professores/as a um determinado ritmo. (...) O que tem menos importância nessa situação é o sentido, a utilidade e o domínio real do que devem aprender. (SANTOMÉ, 1995, p. 160)

Nessa perspectiva, cabe compreender que o modo de viver das crianças de etnias ciganas é diferente das crianças não-ciganas que moram na periferia, na comunidade indígena, no circo e de todas as realidades das outras crianças em modo geral. E, por esse currículo não ser adaptado ou visar as culturas ciganas, essas crianças se sentem a par dos processos de escolarização e não encontram sentido no que é proposto pelas escolas a ser estudado.

O currículo pode ser instrumento de promoção da inclusão social, por isso poderia ser mais dinâmico e menos inflexível, pois "[...] algo que precisa concentrar nossa atenção no currículo é que realidade, que cultura definimos como tal; que cultura pressupomos 
como existente e como válida e que cultura necessitamos transformar." (SANTOMÉ, 1995, p. 165).

Ainda de acordo com Santomé (1995) os currículos trazem e reforçam as culturas hegemônicas e anulam, ou objetivam anular as culturas das minorias na sociedade, silenciando-as e são estereotipando-as ainda mais. São ausentes nos currículos as culturas infantis, a terceira idade; as etnias ciganas; as mulheres; os LGBT; a classe trabalhadora; o Terceiro Mundo, entre outros.

Hall (2006) afirma que as culturas nacionais são as principais fontes de identidade cultural e precisam ser pensadas no plural. $O$ autor reflete sobre a identidade cultural nacional e os deslocamentos que a globalização provocou, revelando o cenário crítico que envolve a noção de identidade nacional que a sociedade constrói e representa:

(...) as identidades nacionais não são coisas com as quais nascemos, mas são formadas e transformadas no interior da representação. Nós só sabemos o que significa ser "inglês" devido ao modo como a "inglesidade" (Englichness) veio a ser representada - como um conjunto de significados - pela cultura nacional. Segue-se que a nação não é apenas uma entidade política, mas algo que produz sentidos um sistema de representação cultural. (HALL, 2006, p. 49)

De acordo com Hall (2006) a cultura nacional contribuiu para a criação de padrões de alfabetização universais, a escolha de uma língua como dominante, como padrão para a comunicação de todos os indivíduos com a nacionalidade local. Mantendo a cultura homogênea mantem-se as instituições nacionais e os sistemas de educação.

Nesse sentido, convém destacar que a Base Nacional Comum Curricular (BRASIL, 2018), de acordo com o governo federal brasileiro, proporcionará para a Educação Básica o direito de aprender e desenvolver habilidades para todas as crianças, sejam elas alunas da escola pública ou privada. Mas cabem questionamentos, pois a defesa para uma Base Nacional Comum para o currículo se baseia em ofertar uma educação de qualidade para os diferentes grupos da sociedade no país, porém especialistas da educação afirmam que os interesses privados de partidos políticos e instituições capitalistas estão sendo colocados em primeiro lugar deixando por último o compromisso com a educação.

Rodrigues (2019) afirma que as reformas têm o objetivo de uniformizar os conteúdos dos currículos e fazer com que os indivíduos deixem de discutir, reivindicar as necessidades de seu grupo cultural.

Ainda de acordo com Rodrigues (2019) no decorrer da história é possível identificar que as etnias ciganas foram invisibilizadas pelos currículos, acarretando no desinteresse dos indivíduos de etnias ciganas em fazer parte das instituições de educação. Essa exclusão é mais visível pela língua oficial do país, que é a língua portuguesa e os indivíduos de etnias ciganas usam um dialeto para se comunicarem, e este não é reconhecido, os obrigando a se comunicarem em uma língua diferente. Assim sendo, é necessário refletir 
sobre as diferentes culturas e o currículo, pois ainda existem lacunas sobre esses assuntos, principalmente na educação.

Na próxima sessão iremos discorrer sobre a metodologia utilizada para a construção deste artigo.

\section{METODOLOGIA}

Para a construção desse artigo realizamos uma revisão de literatura sobre como as crianças de etnias ciganas são retratadas nos processos escolares em parte de uma revisão da produção acadêmica.

No livro "A bússola do escrever", Bianchetti e Machado (2006) afirmam que a produção do conhecimento é coletiva de toda a comunidade acadêmica, "um processo de busca, no qual cada nova investigação se insere, complementando ou contestando contribuições anteriormente dadas ao estudo do tema." Bianchetti e Machado (2006, p. 27). É necessário que o pesquisador se organize dentro do processo de pesquisa, analise com criticidade, compare e contraste as diferentes abordagens, avaliando assim o peso dos resultados da pesquisa.

As investigações realizadas nas produções acadêmicas sobre as Etnias Ciganas presentes no Brasil envolveram duas etapas:

- Na primeira etapa, buscamos por teses e dissertações acadêmicas produzidas sobre o tema no BDTD- Banco de Teses e Dissertações da Capes, no Google e no Google Acadêmico eScielo. Os descritores utilizados na pesquisa foram: Etnias Ciganas e Educação com as palavras-chave crianças ciganas + escola.

- Na segunda etapa da revisão de literatura, buscamos por artigos científicos no Portal de Periódicos da Capes, no Google e no Google Acadêmico eScielo. Os descritores utilizados foram: Etnias Ciganas e Educação com as palavras-chave crianças ciganas + escola.

Para o desenvolvimento deste artigo classificamos como relevantes os seguintes trabalhos acadêmicos:

1. A monografia intitulada "Educação cigana: perspectivas pedagógicas de uma minoria étnica" (DURANTE, 2009),

2. A dissertação "Pintando borboletas: Processos educativos dos alunos ciganos" (PINTO, 2010);

3. A dissertação de mestrado intitulada "Das tendas às telhas: a educação escolar das crianças ciganas da praça Calon Florânia/ RN" (SILVA, 2012);

4. A dissertação "(RE) Conhecer a cultura cigana: uma proposta de inclusão ao currículo escolar em trindade-GO" (MOTA, 2015);

5. E a tese "Educação e Exclusão Social: a perspectiva dos ciganos e dos não-ciganos" (BAREICHA, 2013). 
Usamos também para desenvolver esse trabalho o livro de Moonen (2011) "Anticiganicismo: os ciganos na Europa e no Brasil".

Elaboramos um quadro (Quadro 1) com as informações básicas sobre o livro e as produções acadêmicas encontradas na pesquisa para a construção da discussão:

Quadro 1: Livro, tese, dissertações e monografia sobre crianças ciganas nas escolas brasileiras.

\begin{tabular}{|c|c|c|c|}
\hline Autor/ Título/ Data & Tipo de Publicação & Local Publicado & Palavras-chave \\
\hline $\begin{array}{l}\text { DURANTE, D. S. D. (2009); } \\
\text { Educação cigana: perspec- } \\
\text { tivas pedagógicas de uma } \\
\text { minoria étnica. }\end{array}$ & Monografia & $\begin{array}{l}\text { Instituto Superior de } \\
\text { Educação Carlos Cha- } \\
\text { gas (ISEECC), Juiz de } \\
\text { Fora-Minas Gerais }\end{array}$ & $\begin{array}{l}\text { Educação; Ciganos; } \\
\text { Etnias. }\end{array}$ \\
\hline $\begin{array}{l}\text { PINTO, A. K. P. (2010); } \\
\text { Pintando borboletas: proces- } \\
\text { sos educativos dos alunos } \\
\text { ciganos. }\end{array}$ & Dissertação & $\begin{array}{l}\text { Universidade Federal do } \\
\text { Espírito Santo. } \\
\text { Pós- Graduação em } \\
\text { Educação, com ênfase } \\
\text { em na linha de pesquisa } \\
\text { Diversidade e Práticas } \\
\text { Educacionais Inclusivas. }\end{array}$ & $\begin{array}{l}\text { Ciganos; Diversidade; } \\
\text { Inclusão Escolar. }\end{array}$ \\
\hline $\begin{array}{l}\text { MOONEN, F. (2011); Antici- } \\
\text { ganismo e políticas ciganas } \\
\text { na Europa e no Brasil. }\end{array}$ & Livro & $\begin{array}{l}\text { Google Acadêmico } \\
3^{\text {a }} \text { edição digital revista e } \\
\text { atualizada Recife }-2011\end{array}$ & $\begin{array}{l}\text { Ciganos; Anticiganismo; } \\
\text { Direitos ciganos; Políti- } \\
\text { cas ciganas; Movimento } \\
\text { Cigano; Antropologia; } \\
\text { História. Europa; Brasil. }\end{array}$ \\
\hline $\begin{array}{l}\text { SILVA, F. J. O. (2012); Das } \\
\text { tendas as telhas: A educação } \\
\text { escolar das crianças ciganas } \\
\text { da praça Calon - Florânia/ } \\
\text { RN. }\end{array}$ & Dissertação & $\begin{array}{l}\text { Universidade Federal do } \\
\text { Rio Grande do Norte. } \\
\text { Centro de Ciências So- } \\
\text { ciais Aplicadas. Departa- } \\
\text { mento de Educação. } \\
\end{array}$ & $\begin{array}{l}\text { Ciganos; Cultura esco- } \\
\text { lar; Diversidade cultural; } \\
\text { Direitos humanos. }\end{array}$ \\
\hline $\begin{array}{l}\text { BAREICHA, L. C. F. (2013); } \\
\text { Educação e Exclusão Social: } \\
\text { a perspectiva dos ciganos e } \\
\text { dos não ciganos. }\end{array}$ & Tese & $\begin{array}{l}\text { Programa de Pós-Gra- } \\
\text { duação em Educação da } \\
\text { Faculdade de Educação } \\
\text { da Universidade de Bra- } \\
\text { sília/UnB. }\end{array}$ & $\begin{array}{l}\text { Ciganos; Representa- } \\
\text { ções Sociais; Exclusão } \\
\text { Social; Sociodrama. }\end{array}$ \\
\hline $\begin{array}{l}\text { MOTA, M. L. R. (2015); (RE) } \\
\text { Conhecer a cultura cigana: } \\
\text { uma proposta de inclusão ao } \\
\text { currículo escolar em trinda- } \\
\text { de-GO. }\end{array}$ & Dissertação & $\begin{array}{l}\text { Universidade Federal } \\
\text { de Goiás - Programa de } \\
\text { Pós-Graduação em Ensi- } \\
\text { no na Educação Básica } \\
\text { (Profissional). }\end{array}$ & $\begin{array}{l}\text { Ensino de história; } \\
\text { Cultura; Ciganos; Currí- } \\
\text { culo; Inclusão; }\end{array}$ \\
\hline
\end{tabular}

Fonte: Quadro elaborado pelas autoras (2019).

Os trabalhos selecionados para a revisão de literatura são do período de 2009 a 2015. Selecionamos um livro, uma tese de doutorado, três dissertações de mestrado e uma monografia. A tese selecionada é de Brasília, região Centro-Oeste do país. Quanto às dissertações: uma é do Estado do Rio Grande do Norte, outra é do Estado do Espírito Santo, e a terceira é do Estado de Goiás, regiões Nordeste, Sudeste e Centro-Oeste do país, respectivamente. O livro de autoria de Frans Moonen, que está em sua terceira edição, foi publicado em Recife, cidade localizada na região Nordeste do país. A monografia é de Juiz de Fora, cidade do Estado de Minas Gerais, região Sudeste do Brasil. 
A seguir discutiremos como as crianças de etnias ciganas são retratadas nos processos escolares.

\section{ANÁLISES E RESULTADOS}

Nesta sessão será apresentada a revisão da produção científica sobre a temática dos processos escolares para crianças de etnias ciganas a partir dos dados coletados na revisão de literatura realizada.

Durante (2009) realizou um trabalho de conclusão do curso de Pedagogia intitulado: "Educação cigana: perspectivas pedagógicas de uma minoria étnica" (DURANTE, 2009), onde discute a exclusão sofrida por crianças de etnias ciganas no ambiente escolar.

A autora afirma que no percurso de elaboração de seu trabalho sentiu a falta de mais estudos historiográficos sobre os povos de etnias ciganas, e essa insuficiência de trabalhos acadêmicos sobre a temática contribui para que haja a intolerância e o preconceito para com os ciganos.

De acordo com Durante (2009), por falta de documentos, não há como afirmar se as crianças de etnias ciganas frequentavam as escolas no início da colonização do país, quando começaram a imigrar para o Brasil, mesmo que alguns documentos e jornais da época afirmem que os ciganos tinham boa renda.

A autora Pinto (2010) em sua dissertação de mestrado "Pintando borboletas: processos educativos dos alunos ciganos", afirma que seu objetivo foi conhecer os processos educativos dos estudantes de etnias ciganas. A sua pesquisa se desenvolveu em dois acampamentos ciganos e em duas escolas, no Estado do Espírito Santo.

Segundo Pinto (2010), a escola não considera em seus processos educativos as etnias ciganas, porque os professores desconhecerem essas etnias conduzem as suas práticas sem considerar os alunos de cultura cigana. Invisibilizar as etnias ciganas, no ambiente escolar, podem "produzir algumas tensões geradoras de novas/ outras práticas nas salas de aula" (PINTO, 2010, p. 132). São necessárias práticas educacionais que comtemplem as diversidades culturais, como os ciganos, os indígenas, os negros, os circenses, entre outros, que fazem parte da realidade do currículo brasileiro.

Pinto (2010) afirma que o índice de analfabetos entre os indivíduos de etnias ciganas é alto porque nas comunidades nômades os mais novos aprendem com os mais velhos, que são em maioria analfabetos e consideram que o que é ensinado na escola não tem valor significativo e cultural para eles.

No livro "Anticiganicismo: os ciganos na Europa e no Brasil", o autor, Moonen (2011) discute como os indivíduos de etnias ciganas são tratados no Brasil e na Europa. De acordo com Moonen (2011), as informações sobre os povos de etnias ciganas são escassas no Brasil, pois a quantidade e a qualidade dos estudos científicos são superficiais.

De acordo com o mencionado autor (2011), no Brasil o "Anticiganismo" é recente em termos de pesquisa, mas o termo já existe há algum tempo em outras línguas como 
no inglês e o alemão. O anticiganismo pode ser definido como doutrinas ofensivas contra os povos de etnias ciganas e que têm medidas discriminatórias e políticas contrárias aos direitos desses povos. Dessa forma, quando o currículo e a instituição escolar invisibilizam indivíduos de etnias ciganas, ou até mesmo se recusam a realizar matrícula, estão tendo atitudes anticiganicistas.

E, com relação a educação para os indivíduos de etnias ciganas, Moonen (2011), afirma que:

\begin{abstract}
A escolarização dos filhos de nômades deve ser encorajada pelos métodos mais apropriados, visando a integração destas crianças no sistema escolar normal. (...) Os nômades e seus filhos devem efetivamente poder beneficiar-se das diferentes possibilidades existentes de orientação, de formação ou de reformação profissional. (MOONEN, 2011, p. 147)
\end{abstract}

Medidas como essas, propostas pelo autor, contribuiriam para alavancar a escolaridade dos povos de etnias ciganas e melhorar a inserção deles no mercado de trabalho, melhorando a qualidade de vida desses indivíduos ao longo dos anos.

Na dissertação "Das tendas às telhas: a educação escolar das crianças ciganas da praça Calon Florânia/ RN" Silva (2012) realizou sua pesquisa com um grupo de crianças ciganas da etnia Calon no Estado do Rio Grande do Norte.

Os avós e pais dessas crianças se sedentarizaram na cidade na década de 1980 , construíram suas casas e conquistaram seu espaço, passando a frequentar a escola, aprenderam uma cultura diferente da sua e começaram a usufruir de políticas públicas de outros grupos sociais.

Silva (2012) evidencia a educação familiar e social dos ciganos como prática cultural para as gerações familiares que foram surgindo, mostra também que o trabalho da escola e os elementos teóricos transformaram para melhor o modo de vida das culturas ciganas que lá residem.

Ainda de acordo com Silva (2012), com a introdução da temática sobre a diversidade cultural no currículo escolar, a escola teve como missão superar o preconceito e combater a invisibilidade dessas etnias. Essa árdua tarefa designada a escola, como um dos meios de enfrentar o desrespeito à diversidade cultural, ainda é insuficiente, porque não considera as particularidades da população em que a escola se localiza.

Bareicha (2013) na tese "Educação e Exclusão Social: a perspectiva dos ciganos e dos não-ciganos", investigou as representações sociais, a exclusão social e o "ser cigano" para grupos ciganos e não ciganos do Distrito Federal. Participaram dessa pesquisa indivíduos das etnias Rom, Sinti e Calon, professores, alunos de universidades públicas e particulares.

Os resultados levaram ao porquê da exclusão entre indivíduos ciganos e não- ciganos. E, de acordo com Bareicha (2013) os resultados apontaram o grupo cigano com normas rígidas, cultura tradicional, e, para os entrevistados, os não-ciganos são necessá- 
rios para a realização do comércio, sua principal fonte econômica. O grupo não cigano foi caracterizado como flexível, e tem o cigano com imagem negativa, mas tem interesse em vivenciar sua cultura.

De acordo com Bareicha (2013) a escola é o local de encontros, espaço onde as relações se estabelecem, mas a escola ignora a cultura dos seus alunos de etnias ciganas, deixando de preparar seus professores para acolhê-los e não identificando suas necessidades como grupo. Por isso e pela opção pela vida nômade, a educação não-cigana é desejada apenas se atender às necessidades de subsistência dos povos ciganos.

Entende-se que as políticas públicas precisam atender as necessidades das crianças de etnias ciganas dentro das escolas na tentativa de exterminar o ciclo histórico de exclusão social vivenciado por eles nas escolas brasileiras.

Mota (2015), em sua dissertação de mestrado intitulada "(RE) Conhecer a cultura cigana: uma proposta de inclusão ao currículo escolar em Trindade- GO”, realizou um estudo em três comunidades ciganas no município de Trindade-GO, são elas: Vila Pai Eterno, Samarah e Serra Dourada.

A autora teve como objetivo (re)conhecer a cultura cigana para formalizar e inserir a cultura das etnias ciganas de que residem em Trindade-GO no currículo da Escola Campo que tem muitos alunos dessas etnias, localizada na Vila Pai Eterno. Ela afirma que o respeito e a valorização das diferenças culturais não significam que será preciso aderir a esses valores, mas o objetivo é promover uma educação que visa a construção da cidadania e da igualdade social.

(...) o cigano e os não ciganos só se sentirão parte integrante dessa sociedade quando ambos, o cigano e gadjo, forem reconhecidos como cidadãos, pertencentes a esta sociedade na qual escolheram viver, porém, com sua particularidade respeitada. (MOTA, 2015, p. 112)

Naturalmente os indivíduos sociais são únicos e diferentes, embora se identifiquem por motivos diversos com diferentes grupos, como por raça, sexo, ideologia, cultura, entre outros. Rodrigues (2019) afirma que as características dos indivíduos podem uni-los ou dividi-los, porém isso não torna uns superiores aos outros.

De acordo com Moonen (2011) as organizações das etnias ciganas no país começaram a surgir no ano de 1987, mas as primeiras políticas pró etnias ciganas surgiram somente a partir do ano de 2005. Com relação às políticas criadas para os povos ciganos o autor discorre que "[...] são apenas documentos com boas intenções, quase sempre sem qualquer efeito prático. Principalmente quando tratam de ciganos." (MOONEN, 2013, p. 141).

Mota (2015) relata que os alunos ciganos não obtêm êxito escolar e um dos principais fatores apontados por não-ciganos é a itinerância dos pais, porém é necessário rever esse conceito.

A autora observa que os valores que os indivíduos trazem consigo para o ambiente educacional se conflitam e, consequentemente, os alunos de etnias ciganas não se iden- 
tificam com espaço. Isso acontece porque há um distanciamento da cultura ensinada na escola com a cultura vivida no seio da família. (GABRIEL apud MOTA, 2015).

Ainda de acordo com Mota (2015, p. 105) "é importante, portanto, ressaltar que não há total ausência de leis para com a etnia cigana, mas falta ação no sentido de fazê-las acontecer". O Ministério da Educação precisa intervir e garantir que o direito a educação de qualidade seja assegurado para as crianças de etnias ciganas, evitando a evasão escolar, a distorção idade/ série e proporcionando a permanência desses alunos na escola.

\section{CONCLUSÃO}

Com a realização desse artigo concluímos que as crianças de etnias ciganas são pouco retratadas nas produções acadêmicas da Educação no Brasil. Por isso, as características das culturas ciganas ainda são desconhecidas por muitos da população brasileira.

É prudente que os pesquisadores da educação de crianças de etnias ciganas se envolvam mais com diversidade nas escolas, promovendo novas propostas e ações educativas, uma vez que constataram a dificuldade de abertura dos povos de etnias ciganas.

Constatamos que as pesquisas no ambiente escolar sobre as crianças de etnias ciganas, ainda são insuficientes, mesmo que elas estejam presentes em todas as regiões do país. As crianças de etnias ciganas são retratadas apenas nos papéis das leis.

Identificamos vários documentos sobre os direitos das crianças ciganas itinerantes que residem no Brasil, quanto a educação. Elas podem ser matriculadas nas escolas sem quaisquer imposições por preconceito ou outro. Todavia, aas análises das produções acadêmicas revelam que essas comunidades ainda enfrentam muitos desafios para realizarem o processo de escolarização no Brasil. 


\section{REFERÊNCIAS}

BAREICHA, L. C. F. Educação e exclusão social: a perspectiva dos ciganos e dos não ciganos. 2013. xvi, 378 f., il. Tese (Doutorado em Educação) —Universidade de Brasília, Brasília, 2013.

BIANCHETTI, L.; MACHADO, A. M. N. A bússola do escrever: desafios e estratégias na orientação e escrita de teses e dissertações. 2. Ed. - Florianópolis: Ed. da UFSC; São Paulo: Cortez, 2006.

BORGES, I. C. M. Cidades de portas fechadas: A intolerância contra os ciganos na organização urbana na Primeira República. Dissertação de Mestrado apresentada no Programa de pós-graduação em História da Universidade Federal de Juiz de Fora, 2007.

BRASIL. Ministério da Educação. Secretaria da Educação Básica. Base nacional comum curricular. Brasília, DF, 2018. Disponível em: < http://basenacionalcomum.mec.gov.br/\#/site/inicio>. Acesso em: outubro de 2018.

BRASIL. Projeto de Lei do Senado $n^{\circ}$ 248/ 2015. Disponível em: <https://legis.senado.leg.br/sdleg-getter/documento?dm=4038455\&ts=1539796378197\&disposition=inline $>$. Acesso em: 14 de outubro de 2018.

BRASIL. Ciganos - Documento orientador para os sistemas de ensino, 2014. Disponível em: <http://www.seppir.gov.br/comunidades_tradicionais/copy_of_secadi_ciganos_documento_orientador_para_sistemas_ensino.pdf>. Acesso em: 05 de dezembro de 2018.

BRASIL. Código Civil (2002). Código civil brasileiro e legislação correlata. - 2. ed. - Brasília: Senado Federal, Subsecretaria de Edições Técnicas, 2008.

BRASIL. Lei de Diretrizes e Bases. Lei nº 9.394/96, de 20 de dezembro de 1996.

BRASIL. Lei Federal n. 8069, de 13 de julho de 1990. ECA _ Estatuto da Criança e do Adolescente. Disponível em: <http://www.planalto.gov.br/legislação>. Acesso em: set. 2017.

BRASIL. Constituição Federal de 1988. Brasília, 1988. Disponível em: <http://www.planalto.gov.br/ ccivil_03/constituicao/constituicao.htm>. Acesso em: out. 2017.

DURANTE, D. S. D. Educação Cigana: Perspectivas pedagógicas de uma minoria étnica, 2009. Monografia (Licenciatura em Pedagogia) - Instituto Superior de educação Carlos Chagas, Juiz de Fora, MG, 2009.

DURANTE, D. S. D. Ciganos nas terras do Espírito Santo: Representações sócio-políticas (18701936), 2014. Daniela Simiqueli Durante. -2014. 146 f. Dissertação (mestrado) - Universidade Federal do Espírito Santo.

EMBAIXADA CIGANA. Etnicidades ciganas do Brasil. Disponível em: <http://www.embaixadacigana.org.br/etnicidades_ciganas_no_brasil.html>. Acesso em: 12 de dezembro de 2017.

FRASER, A. História do Povo Cigano. Lisboa: Teorema, 1997. 
GABRIEL, F. M. S. O Multiculturalismo na escola: o caso dos alunos de etnia cigana. 2007. 660f. Dissertação (Mestrado em Relações Interculturais) - Universidade Aberta, Porto, Portugal, 2007.

GUIMARAIS, M. T. S. O associativismo transnacional cigano: identidades, diásporas e territórios. São Paulo: USP, 2012. 229 f. Tese (Doutorado) - Departamento de Geografia, Faculdade de Filosofia, Letras e Ciências Humanas, Universidade de São Paulo, São Paulo, 2012.

HALL, S. A identidade cultural na pós-modernidade / Stuar Hall: tradução Tomaz Tadeu da Silva; Guaracira Lopes Louro - 11 ed. Rio de Janeiro: DP\&A, 2006.

LIBÂNEO, J. C. Pedagogia e pedagogos, pra quê? 7. Ed. São Paulo: Cortez, 2005.

MENDES, M.; MAGANO, Olga; CANDEIAS, Pedro. Estudo nacional sobre as comunidades ciganas. Portugal, 2014. Disponível em: <https://repositorio.iscte-iul.pt/bitstream/10071/15587/1/estudonacionalsobreascomunidadesciganas.pdf>. Acesso em: 20 de maio de 2018.

MOONEN, F. Anticiganismo: os Ciganos na Europa e no Brasil. $3^{a}$ edição. Recife, 2011. Disponível em: <http://www.dhnet.org.br/direitos/sos/ciganos/a_pdf/1_fmanticiganismo2011.pd>: Acesso em: 15 de setembro de 2017.

MOTA, M. L. R. (Re) Conhecer a Cultura Cigana: Uma Proposta de Inclusão ao Currículo Escolar em Trindade-GO. [manuscrito] / Maria Lúcia Rodrigues MOTA. 2015.

PINTO, A. K. P. Pintando Borboletas: processos educativos dos alunos ciganos / Ana Kátia Pereira Pintos. 2010.

RODRIGUES, M. O. S. Crianças ciganas: etnias (in)visibilizadas na educação básica e em projetos sociais / Monique de Oliveira da Silva Rodrigues. -- Maringá, PR, 2019. 135 f.: il. color. figs.

ROMANI, D. Especial Ciganos. Continente, Recife, n 147, p 27, março de 2013.

SANTOMÉ, J. T. As culturas negadas e silenciadas no currículo. In: SILVA, Tomaz Tadeu (Org.). Alienígenas na sala de aula. Petrópolis, RJ: Vozes, 1995. p. 159-177.

SILVA, F. de O. Das tendas às telhas: a educação escolar das crianças ciganas da praça Callon Florânia/ RN. Natal, RN, 2012.

SILVA, T. T.. Documentos de identidade: uma introdução às teorias do currículo. Belo Horizonte: Autêntica, 1999.

SIMÕES, S. R.; JULIANO, D. B. R. Educação cigana: escola para ciganos ou escola com ciganos? In: Anais do IV Simpósio sobre Formação de Professores - SIMFOP. Maio de 2012. Disponível em: < http://www.linguagem.unisul.br/paginas/ensino/pos/linguagem/eventos/simfop/artigos_IV\%20 sfp/_S\%C3\%ADlvia_Sim\%C3\%B5es.pdf>. Acesso em: 10 de fevereiro de 2017.

VENTURA, M. C. S. P. A experiência da criança cigana no Jardim de Infância. Universidade do Minho. Instituto de Estudos da Criança (IEC). Instituto de Ciências Sociais, Braga, 2004. 